\title{
Source biases in midlatitude magnetotelluric transfer functions due to Pc3-4 geomagnetic pulsations
}

\author{
Benjamin S. Murphy ${ }^{*}$ (D) and Gary D. Egbert
}

\begin{abstract}
The magnetotelluric (MT) method for imaging the electrical conductivity structure of the Earth is based on the assumption that source magnetic fields can be considered quasi-uniform, such that the spatial scale of the inducing source is much larger than the intrinsic length scale of the electromagnetic induction process (the skin depth). Here, we show using EarthScope MT data that short spatial scale source magnetic fields from geomagnetic pulsations (Pc's) can violate this fundamental assumption. Over resistive regions of the Earth, the skin depth can be comparable to the short meridional range of Pc3-4 disturbances that are generated by geomagnetic field-line resonances (FLRs). In such cases, Pc's can introduce narrow-band bias in MT transfer function estimates at FLR eigenperiods ( 10-100 s). Although it appears unlikely that these biases will be a significant problem for data inversions, further study is necessary to understand the conditions under which they may distort inverse solutions.
\end{abstract}

Keywords: Magnetotelluric bias, Magnetotelluric source effects, Geomagnetic pulsations, Field-line resonance

\section{Introduction}

The fundamental assumption underlying the magnetotelluric (MT) method is that external source fields have wavelengths that are large compared to the fundamental length scale characterizing electromagnetic (EM) induction in the Earth-that is, the skin depth (e.g., Weidelt and Chave 2012). With the assumption of a quasi-uniform source, the impedance (transfer function, TF, relating electric to magnetic fields at a point on the Earth's surface) is well defined and independent of the actual (large-scale) spatial structure of the source fields. Because EM induction in a conductor is a diffusive process, the impedance and other uniform source TFs used in MT (e.g., vertical magnetic field TFs) should be very smooth functions of frequency (Weidelt 1972). Indeed, excessively rapid variations in TF curves estimated from field data are often taken as evidence of source complications, most often due to relatively short-wavelength anthropogenic EM signals such as electric trains (e.g.,

*Correspondence: murphybe@oregonstate.edu College of Earth, Ocean, and Atmospheric Sciences, Oregon State University, Corvallis, OR, USA
Larsen et al. 1996; Egbert 1997; Egbert et al. 2000). Possible biases in MT TFs due to complications in naturally occurring external sources are also occasionally considered, but generally only at long periods ( $>1000 \mathrm{~s}$ ) and near the auroral or equatorial electrojets (e.g., Viljanen 2012, and references therein).

As part of the EarthScope USArray project (http:// www.usarray.org/researchers/obs/magnetotelluric), longperiod $\left(\sim 10^{1}-10^{4} \mathrm{~s}\right)$ MT data have been acquired since 2006 in a series of short (20-30 day) deployments on a quasi-uniform $70 \mathrm{~km}$ grid. As of this writing, approximately 1000 sites across about half of the continental USA have been occupied (Fig. 1). A significant fraction of the impedances from this dataset displays unphysical "humps" that significantly deviate from the smooth trend of the TF over a narrow range of periods, typically much less than half a decade in width, between 10 and $100 \mathrm{~s}$ (Fig. 2). A conservative marking of sites where impedances clearly exhibit these unphysical features is shown in Fig. 1. A larger fraction of sites, perhaps as great as $15 \%$, show at least some evidence for similar biases of smaller amplitude. The affected sites are most common in, or on the edges of, areas where the Earth is relatively resistive 
(Fig. 1). As increasing resistivity increases the skin depth and makes the quasi-uniform assumption easier to violate, this observation suggests that these humps reflect source bias. In this paper, we provide further evidence for this conclusion and demonstrate that short-wavelength natural sources associated with geomagnetic pulsations (Pc's) can explain the observed biases.

The possibility that Pc's, which in the $~ 10-100$-s period band usually result from geomagnetic field-line resonance (and hence exhibit rapid variations meridionally), might violate the quasi-uniform source assumption has been discussed previously from a theoretical perspective by Pilipenko and Fedorov $(1993,1994)$. Our results demonstrate with a large collection of MT impedance estimates that such source effects can indeed cause problems for the MT method, at least in resistive areas.

\section{The quasi-uniform source assumption in the magnetotelluric method}

Mathematically, the external magnetic field satisfies the quasi-uniform source ("plane-wave") assumption when the skin depth $\delta$ for induced currents is much less than the spatial scale of the source, i.e.,

$$
\lambda(T) \gg \delta=\frac{\sqrt{\rho T}}{2}
$$

where $T$ is the period (in s) of the exciting source harmonic component; $\lambda$ is the spatial wavelength (in $\mathrm{km}$ ) of the source; and $\rho$ is the electrical resistivity (in $\Omega \mathrm{m}$ ) of the region of the Earth in question.

For a one-dimensional Earth, a rigorous mathematical treatment is possible. Dmitriev and Berdichevsky (1979) showed that if the source magnetic field varies linearly over a distance of at least three times the skin depth, the local relationship between electric and magnetic fields will be nearly identical to that obtained with an exactly uniform source. (See also Wait 1954, 1982.) When there are lateral variations in resistivity, a rigorous analysis is not possible, and there is some evidence that source effects may be stronger (e.g., Egbert and Booker 1989). Nonetheless, the fundamental physical intuition remains the same: the inducing external magnetic field should not

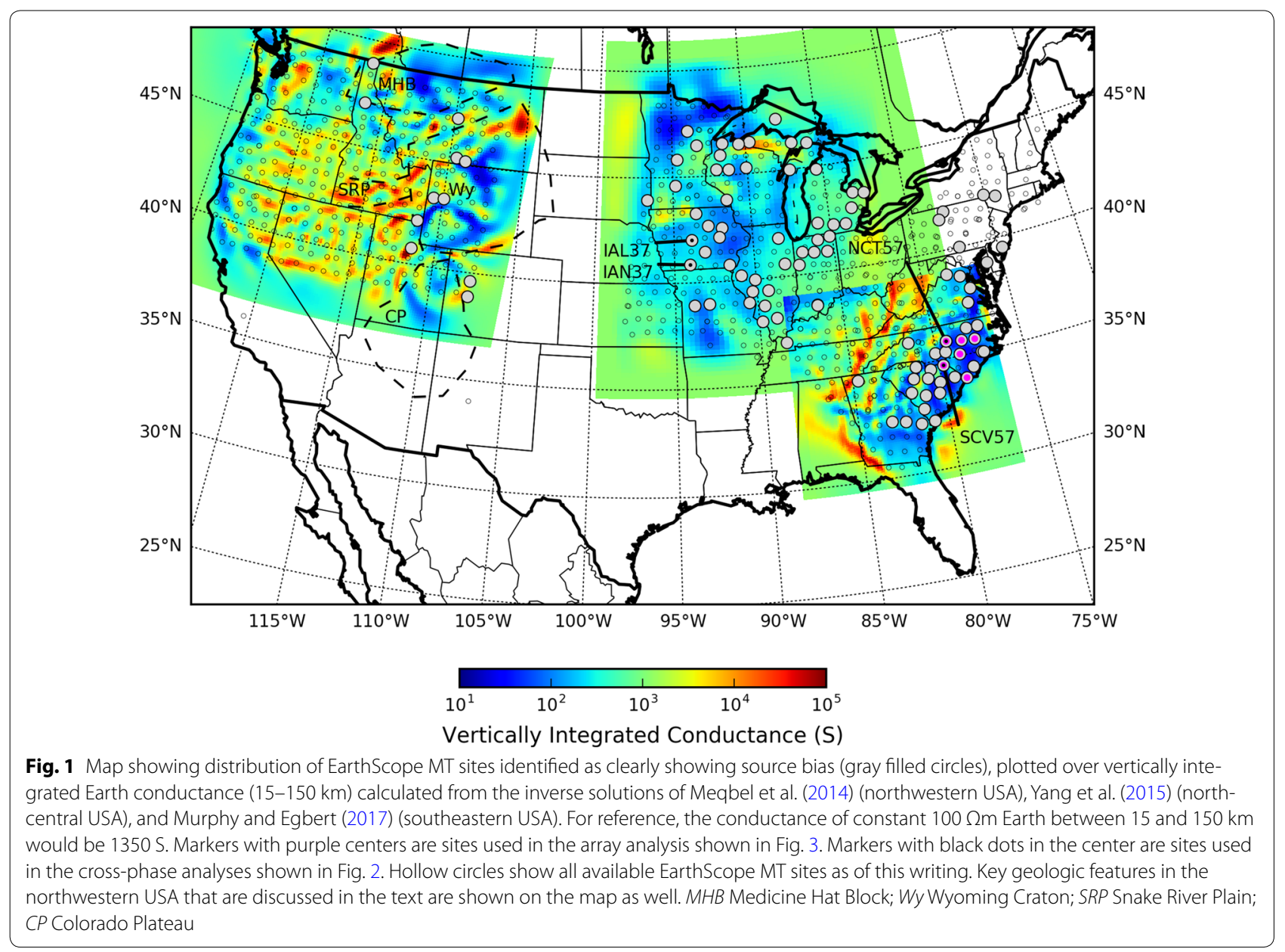



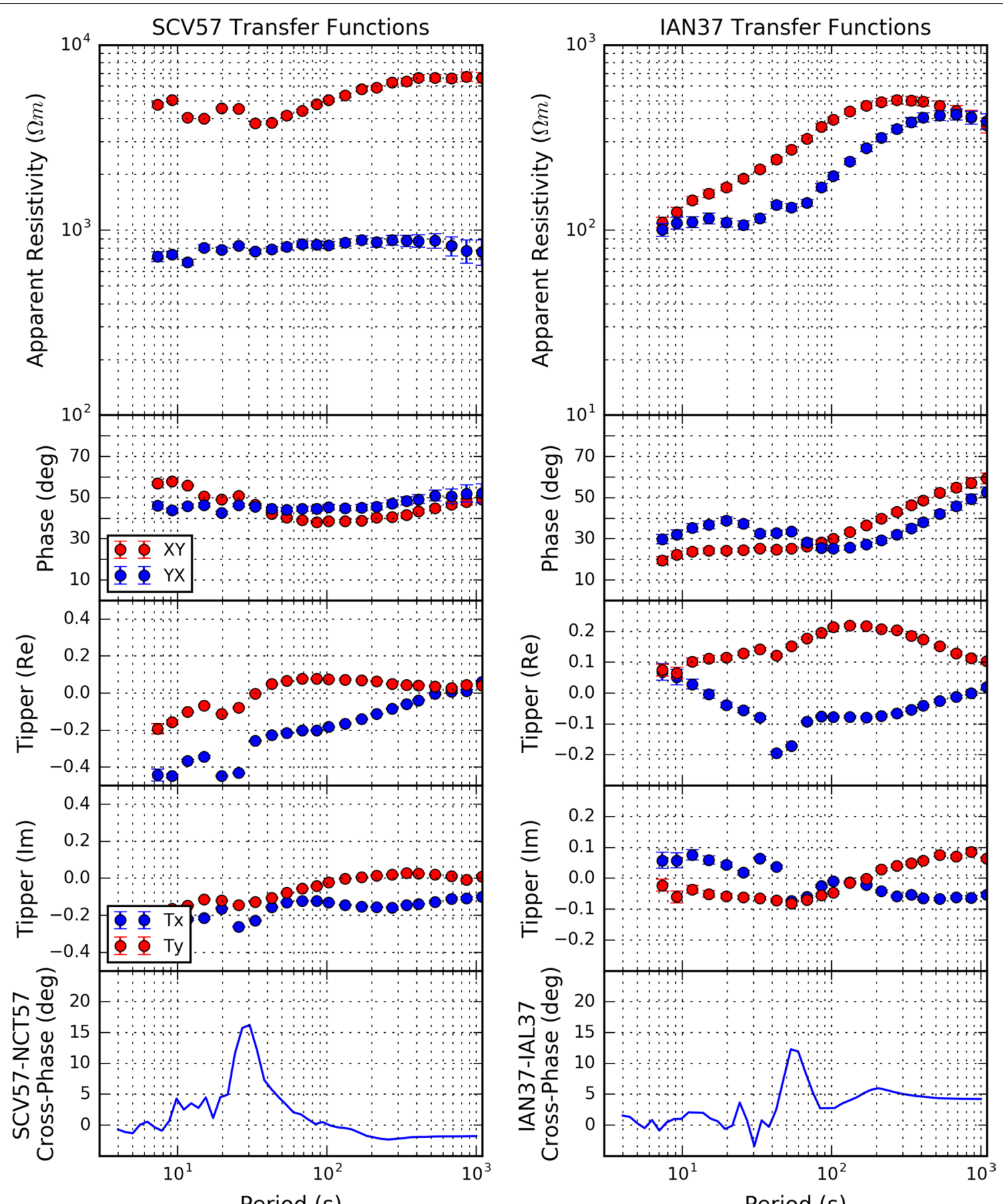

Fig. 2 Transfer functions and cross-phase analyses from sites shown in Fig. 1. The upper four plots in each column display the robustly estimated remote reference TFs for the indicated site. TF estimates were calculated with EMTF (Egbert and Booker 1986). In each of these plots, blue is used to denote TFs that involve the $\mathrm{N}-\mathrm{S}$ magnetic field (X geomagnetic component: $Y X$ impedance element and Tx vertical field TF component) and red is used to denote TFs that involve the E-W magnetic field ( $Y$ geomagnetic component: $X Y$ impedance element and Ty vertical field TF component). The bottom plot in each column shows the calculated time-averaged cross-phase spectra for the specified pair of sites for the $\mathrm{N}-\mathrm{S}(\mathrm{X})$ component of the magnetic field (estimated using the wavelet technique outlined in Waters et al. 2006). (See Additional file 1: Fig. S3 for TFs from NCT57 and IAL37; see Additional file 1: Fig. S4 for plots of the full impedance tensor from SCV57) 
vary significantly over length scales that are several times the skin depth in the Earth.

\section{Geomagnetic pulsations and field-line resonances}

In the $\sim 10-100-s$ period band, geomagnetic pulsations are a dominant component of the geomagnetic power spectrum measured on the Earth's surface (e.g., McPherron 2005). These signals originate beyond the magnetosphere (in the foreshock, bowshock, and/or magnetopause) as ULF hydromagnetic waves that propagate into the magnetosphere through a variety of mechanisms (Hughes 1994; Clausen et al. 2009; Menk 2011). Within the magnetosphere, these hydromagnetic disturbances can excite standing Alfvén waves along geomagnetic field lines (Hughes 1994). A single field line can be pictured as a forced, damped harmonic oscillator (Waters et al. 1991), with the amplitude of the response greatly enhanced at the natural resonant frequency of the field line. (See Additional file 1: Fig. S1 for a graphical summary.) Although this model of field-line resonance (FLR) is very simple, it explains many observed characteristics of Pc's (Hughes 1994).

FLRs drive electrical currents in the ionosphere at the ends of the field lines (McPherron 2005). Ionospheric Pedersen currents (parallel to driving electric field) cancel out the magnetic field of the FLRs, thereby screening their direct signature at the Earth's surface, but eastwest ionospheric Hall currents (perpendicular to driving electric and magnetic fields) produce electromagnetic radiation that is observed on the ground as dominantly north-south magnetic oscillations (McPherron 2005). The FLR signature at the Earth's surface is therefore the result of ionospheric screening processes (Hughes and Southwood 1976; McPherron 2005). Because geomagnetic field lines have distinct resonant frequencies, the resulting magnetic disturbances observed on the ground are nearly monochromatic and highly sinusoidal; they are therefore identified as a type of continuous pulsation (Pc). Pulsations associated with FLRs are generally in the Pc3-4 band ( 10-150 s) (McPherron 2005).

The resonant period of geomagnetic field lines depends on the length of the field line, the magnetic field strength along the field line, and the plasma density along the field line (Hughes 1994; Waters et al. 2006; Menk 2011). Field-line length increases with geomagnetic latitude, so the fundamental FLR period generally increases geomagnetically poleward. Because magnetic field strength and plasma density are highly dynamic, the FLR period fluctuates in time; for example, daily variations in plasma density cause daily variations in FLR period (Poulter et al. 1988).

On the Earth's surface, the width of a given FLR is of order $100 \mathrm{~km}$ (Hughes 1994; Menk 2011; Chi et al.
2013). As can be seen from the simple harmonic oscillator model of an FLR as well as from more complex theoretical and empirical treatments, amplitudes will be enhanced over a limited range of latitudes centered on the main resonant field line (several hundred kilometers), and there will be a $180^{\circ}$ phase shift moving geomagnetically north-south through this zone (Waters et al. 1991; Hughes 1994; Chi and Russell 1998; Kawano et al. 2002; see also Additional file 1: Fig. S1). Although large-scale magnetospheric perturbations (fast-mode compressional waves) are also observed on the ground in this same period range (Kawano et al. 2002; Chi et al. 2013), when FLRs are excited, their effects typically dominate the total incident field at the Earth's surface (Ádám et al. 2005). Therefore, near the (latitude-dependent) resonant frequency, the total source magnetic field can vary rapidly over only a few hundred kilometers in the geomagnetic north-south direction. Where the Earth is in bulk moderately conductive $(\sim 100 \Omega \mathrm{m})$, from Eq. 1 the skin depth at an FLR period of $30 \mathrm{~s}$ will be $\sim 30 \mathrm{~km}$, still relatively small compared to Pc source wavelengths. However, if the Earth is in bulk relatively resistive $(\sim 1000 \Omega \mathrm{m}$ or more), the skin depth at $30 \mathrm{~s}$ will be $\sim 90 \mathrm{~km}$ or more, comparable to source wavelengths expected for Pc's. More resistive Earth or a longer-period FLR will make the skin depth an even larger fraction of the spatial scale of the Pc's. Clearly, over resistive Earth the quasi-uniform source assumption of the MT method can be violated in the Pc3-4 band.

\section{Data and methods}

In order to investigate the link between field-line resonances and biases in MT TFs, we utilized two different analyses to explore the spectral and spatial characteristics of the source horizontal magnetic fields. We used EarthScope MT time series and robust remote reference TF estimates (Kelbert et al. 2011), which are archived for community use with IRIS (http://ds.iris.edu/spud/emtf).

To detect the presence and period localization of FLRs in the EarthScope MT time series, we use the cross-phase technique (e.g., Waters et al. 1991; Chi and Russell 1998; Kawano et al. 2002; Menk et al. 2004; Waters et al. 2006; Chi et al. 2013; see also Additional file 1: Fig. S1 and supplemental text), a well-established analytical method in ULF space physics research. Because the phase of the FLR changes significantly when moving meridionally through a resonance, the phase difference as a function of period (cross-phase) between two sites spaced at the length scale of an FLR should show a sharp peak at the resonance period (Waters et al. 1991; Chi and Russell 1998; Kawano et al. 2002). We selected pairs of sites in which the two sites lie roughly on the same geomagnetic meridian and are separated in latitude by $\sim 70-200 \mathrm{~km}$. With the $\mathrm{N}-\mathrm{S}$ 
magnetic field time series from these pairs of sites (the $\mathrm{X}$ geomagnetic component), we used the wavelet-based cross-phase calculation approach documented by Waters et al. (2006). However, because the MT method uses a time-averaged frequency-domain analysis, we then averaged the cross-phase estimates in time. The resulting cross-phase curve thus provides an estimate of the timeaveraged FLR period appropriate for comparison to the MT TF estimates. Note that, due to induced currents in the Earth, there may be spatially localized anomalous horizontal magnetic fields that also cause variations in the cross-phase spectrum. Because these induced internal fields result from a diffusive induction process, they will be smooth and broadband, in contrast to the sharp (localized in period) phase signature of FLRs.

To further characterize the spatial patterns of EM fields at the analyzed MT sites, we applied the array processing approach of Egbert and Booker (1989; see also Egbert 1997), to small ( 6-10 site) arrays of simultaneously occupied EarthScope sites. We specifically used the processing scheme extended by Smirnov and Egbert (2012); this technique is essentially a robust frequencydomain principal component analysis (PCA) to allow for missing data and only partial overlap of site occupation intervals. The PCA scheme decomposes the frequencydomain data from the array (including all five channels from each MT site, so 30-50 channels total) into a small number (typically $2-5$ ) of coherent spatial modes. The analysis provides estimates of incoherent noise levels in each channel and signal levels in each spatial mode. If the uniform source assumption held exactly, only two modes (corresponding to uniform source polarization parameters) would have power above the incoherent noise level; additional modes are generally indicative of source complications (either natural or anthropogenic). The spatial modes combine information about both source spatial structure and the response of the Earth.

\section{Results}

Analyses of station pairs across the USA reveal sharp peaks in the cross-phase spectra in the Pc3-4 range, thereby confirming the signature of FLRs in the EarthScope magnetic field time series. Two examples of these analyses are shown in Fig. 2, in both cases for sites located over resistive Earth (Fig. 1) where skin depths will be large. Note that the peak in the cross-phase spectrum shifts to longer periods at higher geomagnetic latitude. At both pairs of sites, the peak period is consistent with expectations for FLRs (e.g., Poulter et al. 1988). These peaks imply a phase shift of $\sim 15^{\circ}$ (on average) over the distance between the stations in each pair $(\sim 150 \mathrm{~km})$ in the same period range as the biases in the corresponding MT TFs, which are also shown in Fig. 2. This correlation is strong evidence that the short spatial scale of the FLRs is contaminating the TF estimates where the skin depth is large. A similar analysis of sites in the relatively conductive Snake River Plain still shows the presence of the FLR cross-phase peak, but the TFs do not show any clear biases (see Additional file 1: Fig. S2). Our analysis of a large number of station pairs shows that FLR signatures are always present in the EarthScope magnetic field data (and consequently always induce telluric currents), but apparently only where skin depths become large do they bias the TF estimates.

The robust PCA approach provides further information about source spatial structure associated with FLRs and the observed TF biases. Results for a small array located over the highly resistive Piedmont Resistor of Murphy and Egbert (2017), where all six sites show TF biases at $\sim 30 \mathrm{~s}$ (analyses from two of these sites are shown in Fig. 2), are shown in Fig. 3. In Fig. 3a, power in signalto-noise ratio units is plotted as a function of frequency for the first six modes. Over the same band of periods where the cross-phase analysis identifies the FLR (and where the TF biases appear), a third mode rises significantly above the estimated background incoherent noise level (defined to have an SNR of 0 on this plot). The three estimated PCA modes in this band likely represent a mixture of nearly uniform magnetic field sources and N-S gradients associated with FLR. Following the approach of Egbert (2002), we seek linear combinations of the three estimated modes that most closely approximate uniform magnetic sources, polarized linearly in the $\mathrm{N}-\mathrm{S}$ and $\mathrm{E}-\mathrm{W}$ (geomagnetic) directions (Fig. 3b, c). The dominant signal remaining after removing these quasi-uniform components (Fig. 3d) exhibits strong meridional gradients in both the horizontal magnetic and electric field components. The vertical component of magnetic field (shown by the circles) is also very large (comparable to horizontal components). Note that the fine-scale heterogeneity in the spatial modes reflects complexities in the Earth rather than source complications or noise. This is particularly true of the electric field vectors, which can be strongly distorted by even small-scale superficial heterogeneity.

The general pattern illustrated in Fig. 3 holds in subarrays across the continental USA. Again, it is clear that short-wavelength gradients in horizontal magnetic fields associated with Pc's are present in all the EarthScope MT data, but only where skin depths become large do their effects become noticeable in the MT TF estimates.

\section{Discussion}

As the sharp peaks in the cross-phase spectra of Fig. 2 indicate, there are significant phase shifts in source magnetic fields between sites that are meridionally separated on the order of $100 \mathrm{~km}$ (See also Additional file 2: Fig. S8). 


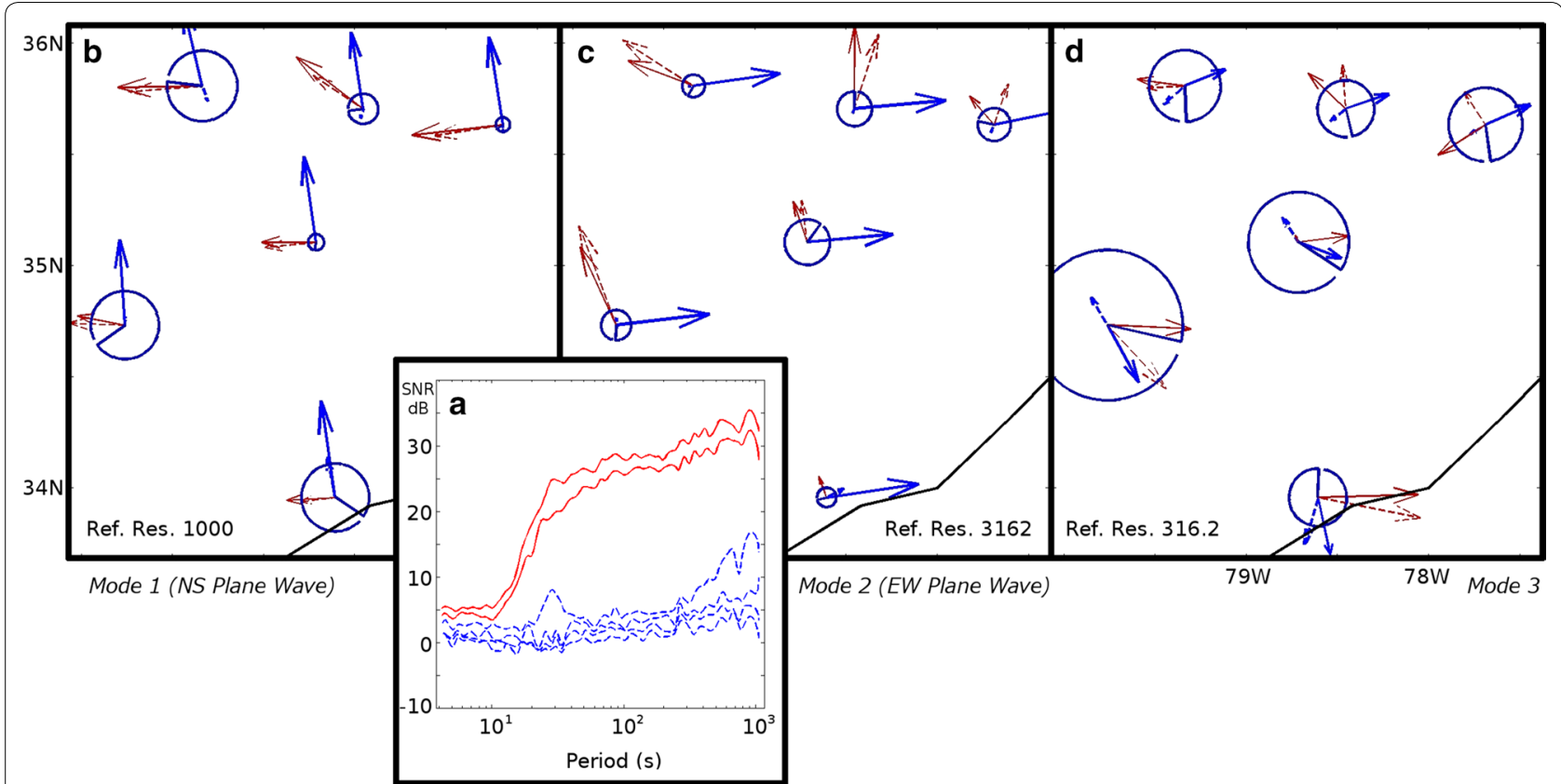

Fig. 3 Results from frequency-domain robust principal component analysis of electric and magnetic fields from the array shown in Fig. 1, which includes the two sites from the southeastern USA used in Fig. 2. a Power spectrum of six dominant modes, given in signal-to-noise units expressed in decibels (dB). Signal power above $0 \mathrm{~dB}$ indicates that the mode is above the incoherent noise level and therefore significant. If the uniform source assumption that underlies the MT method held exactly, there would only be two significant modes (shown in red). In the FLR period band for this array $(\sim 20-40 \mathrm{~s})$, the curve for the third mode becomes significant. Additional significant modes at longer periods are also associated with source effects (primarily in the vertical magnetic fields) due to increasing skin depths with respect to large-scale source structure (e.g., Jones and Spratt 2002). b-d Linear combinations of the first three spatial modes at a period of $26 \mathrm{~s}$, displayed as complex vectors plotted on a map of array sites. The first two panels show linear combinations, defined following the approach in Egbert (1997), that best approximate uniform magnetic sources, linearly polarized geomagnetically $\mathrm{N}-\mathrm{S}$ and $\mathrm{E}-\mathrm{W}$. Panel $\mathbf{d}$ represents the remaining signal in the first three modes. This mode exhibits a clear northsouth spatial gradient and very large vertical magnetic components, consistent with expectations for a spatially localized FLR signature. In these plots, horizontal magnetic (electric) fields are shown with blue (red) arrows, with real parts solid and imaginary parts dashed. The vertical magnetic field is shown with a blue circle, scaled as for the horizontal components to indicate amplitude, with the position of the drawn radius denoting phase. To scale the lengths of electric and magnetic field vectors in a physically meaningful way, a reference Earth resistivity (given in each panel) is assumed

As these phase shifts occur in the Pc3-4 band and generally move to longer periods at higher geomagnetic latitudes, they are associated with localized, narrow-band FLRs. In resistive areas where the skin depth can become comparable to the spatial scale of FLRs $(\sim 100 \mathrm{~km})$, the quasi-uniform-source assumption of the MT method will be violated.

Because FLRs essentially cause a meridionally localized amplification of magnetic field variability in the Pc3-4 band, the signal associated with them will be spatially coherent (both zonally and meridionally). Therefore, these biases cannot be removed by remote reference processing. (Note the TF estimates shown in Fig. 2 and Additional file 1: Fig. S2 are robust remote reference estimates; Additional file 1: Fig. S5 shows that using different remote sites does not significantly change the biases.) Exclusion of time series segments with significant Pc activity can mitigate the resulting biases in TF estimates somewhat (see Additional file 1: Fig. S6). However, we have not been able to completely remove these biases with simple data selection procedures. Furthermore, the Pc's associated with FLRs appear to be a major source of signal for the MT method in the Pc3-4 band, at least at midlatitudes. During times without clear Pc activity there is little MT signal, which can result in noisy and unreliable TF estimates (Ádám et al. 2005). It is thus unclear if the source biases we have identified in the Pc3-4 band can be completely avoided.

\section{Pc's and the 3D earth}

The spatial distribution of EarthScope MT sites that display source biases in impedance estimates (Fig. 1) suggests that to first order this problem will be most severe directly over resistive Earth. This pattern is clearest in the central USA, over resistive Archean- to Paleoproterozoicaged cratonic lithosphere that was imaged by Yang et al. (2015), and in the southeastern USA, over the highly resistive Piedmont Resistor of Murphy and Egbert (2017). 
However, there are many sites over resistive areas where biases in the Pc3-4 band are not clear. Furthermore, in the western USA, stations that appear most affected are often on the edges of, rather than directly above, the resistive Wyoming Craton, Medicine Hat Block, and Colorado Plateau (imaged by Meqbel et al. 2014). The exact details of how the short spatial scale of Pc's interacts with three-dimensional conductivity structures are likely more complex than the simple skin depth argument suggests. Large conductivity contrasts as well as high resistivity may be important determinants of the impact of shortwavelength sources on MT TF bias. Further numerical modeling work is necessary to explore this possibility.

\section{Implications for MT data inversions}

As Fig. 2 indicates, the effect of Pc-related source biases on MT impedances is clearly noticeable with good quality data. However, the effect is still relatively small compared to the uncertainties and inaccuracies inherent in MT inversions. We therefore consider it unlikely that these small biases in impedances will lead to substantial biases in inversion results, especially if appropriate error floors are set. However, there may be circumstances in which the impacts on inverse solutions will be more severe, so this issue deserves more careful consideration. As also indicated by Fig. 2, in comparison with the effect on impedance data, the effect on the vertical magnetic field TFs (tippers) generally appears to be more significant. This is perhaps to be expected, as tippers are more dependent on source characteristics than impedances (e.g., Jones and Spratt 2002). Biases in the tippers may sometimes be large enough that these data should be excluded from an inversion. In general, care should be taken in working with MT data in the FLR band, especially in places where the Earth is relatively resistive.

Our observations of Pc-related biases in MT TFs also demonstrate the necessity of using error floors in MT data inversions. In the case documented here, the biases associated with violation of the assumptions of the MT method are clearly noticeable; however, it is possible that measured data could include other far more subtle biases that could go unnoticed and unappreciated. Therefore, error floors are necessary to reflect the reality of working with MT data: intrinsic complexities and necessary approximations in the MT method, from data acquisition to data inversion, make it impossible to perfectly model real data.

\section{Implications for earth structure}

Finally, we note that the widespread appearance of biases in the Pc3-4 band in MT TFs can be a useful first-order indicator of resistive Earth. For example, the pervasive presence of biases in the TF estimates from the Piedmont and Coastal Plain regions of the southeastern USA is an additional strong line of evidence for the highly resistive, highly anomalous Piedmont Resistor documented by Murphy and Egbert (2017).

\section{Conclusions}

Despite abundant empirical and theoretical study of FLRs in the space physics literature, that they can bias MT TFs at relatively short periods $(\sim 10-100 \mathrm{~s})$ and at relatively low latitudes $\left(<60^{\circ}\right)$ has not been widely appreciated by the MT community. The potential for biases in MT TFs posed by Pc's has been acknowledged theoretically before (e.g., Pilipenko and Federov 1993, 1994), and it was even pointed out at the very inception of the MT method. In a 1953 letter to Louis Cagniard, one of the pioneers of MT, James R. Wait raised the problem of geomagnetic pulsations (at the time called 'micropulsations'):

The current system in the upper atmosphere giving rise to short period (less than $60 \mathrm{~s}$ ) variations of the magnetic [field] such as "micro pulsations" are confined to a limited region as observed by several investigators. In this case the infinite [current] sheet representation is not permissible.

Cagniard replied to Wait's concern by flatly dismissing the potential for a violation of the plane-wave approximation:

I am entirely in accord with you except regarding the question of the micropulsations being limited to a very restricted region. Only yesterday, M. Migaux, director of the Compagnie Générale de Geophysique, the man who "sees" the most micropulsations, told me that they do not exist except where there are industrial disturbances. Along with St. Thomas, we have to see to believe.

(From letters published in Vozoff 1986, pp. 41, 43) Now, using real data, we have shown that at midlatitudes $\left(30-50^{\circ}\right)$ geomagnetic pulsations in the Pc3-4 band ( 10-100 s) associated with field-line resonances can and do violate a fundamental assumption of the MT method. They therefore can bias MT TF estimates where skin depths are large. Clearly, the infinite current sheet representation in the MT technique may at times be impermissible. Our observations herein stress the importance of understanding the magnetospheric/ionospheric sources that the MT technique exploits, of appreciating when the source fields may violate the assumptions of the MT method, and of carefully considering possible biases when interpreting and inverting estimated MT responses. 


\section{Additional files}

Additional file 1: Figures S1-S7. Also, further mathematical explanation of the cross-phase technique.

Additional file 2: Figure S8. Animation showing horizontal magnetic field vector motion (as equivalent ionospheric currents) in the Pc3-4 band. The $B x$ and By time series were band-pass filtered to 10-100 s and are plotted in map view as vectors that represent the equivalent ionospheric currents that would generate the horizontal magnetic field observed on the ground. (The B-field vectors are rotated $90^{\circ}$ clockwise to get the equivalent ionospheric currents.) The horizontal magnetic field is coherent zonally (E-W), but there is a clear meridional (N-S) phase shift in vector motions.

\section{Abbreviations}

MT: Magnetotelluric; TF: Transfer function; PC: Continuous pulsation; FLR: Fieldline resonance; PCA: Principal component analysis.

\section{Authors' contributions}

BSM completed these analyses under the guidance and supervision of GDE. Both authors read and approved the final manuscript.

\section{Acknowledgements}

We are grateful to Robert McPherron for helping us to understand the physics of geomagnetic pulsations and field-line resonances. We also thank Maxim Smirnov for his help with the robust array processing program. We thank two anonymous reviewers and editor Juanjo Ledo for a helpful review of the manuscript.

\section{Competing interests}

The authors declare that they have no competing interests.

\section{Availability of data and materials}

MT time series data can be accessed through the IRIS DMC (http://ds.iris.edu/ $\mathrm{ds} /$ nodes/dmc/). MTTFs are available through the IRIS SPUD EMTF portal (http://ds.iris.edu/spud/emtf).

\section{Consent for publication}

Not applicable.

\section{Ethics approval and consent to participate}

Not applicable.

\section{Funding}

This research was supported by the NSF Graduate Research Fellowship Program under Grant 1314109-DGE and by NSF Grant EAR1447109.

\section{Publisher's Note}

Springer Nature remains neutral with regard to jurisdictional claims in published maps and institutional affiliations.

Received: 6 November 2017 Accepted: 10 January 2018 Published online: 22 January 2018

\section{References}

Ádám A, Verõ J, Szendrõi J (2005) Solar eclipse effect on geomagnetic induction parameters. Ann Geophys 23:3487-3494. https://doi.org/10.5194/ angeo-23-3487-2005

Chi PJ, Russell CT (1998) An interpretation of the cross-phase spectrum of geomagnetic pulsations by the field line resonance theory. Geophys Res Lett 25(24):4445-4448. https://doi.org/10.1029/1998GL900211

Chi PJ, Engebretson MJ, Moldwin MB, Russell CT, Mann IR, Hairston MR, Reno M, Goldstein J, Winkler LI, Cruz-Abeyro JL, Lee D-H, Yumoto K, Dalrymple
R, Chen B, Gibson JP (2013) Sounding of the plasmasphere by Midcontinent MAgnetoseismic Chain (McMAC) magnetometers. J Geophys Res Space 118:3077-3086. https://doi.org/10.1002/jgra.50274

Clausen LBN, Yeoman TK, Fear RC, Behlke R, Lucek EA, Engebretson MJ (2009) First simultaneous measurements of waves generated at the bow shock in the solar wind, the magnetosphere and on the ground. Ann Geophys 27:357-371. https://doi.org/10.5194/angeo-27-357-2009

Dmitriev VI, Berdichevsky MN (1979) The fundamental model of magnetotelluric sounding. Proc IEEE 67(7):1034-1044. https://doi.org/10.1109/ PROC.1979.11386

Egbert GD (1997) Robust multiple-station magnetotelluric data processing. Geophys J Int 130:475-496. https://doi.org/10.1111/j.1365-246X.1997. tb05663.x

Egbert GD (2002) Processing and interpretation of electromagnetic induction array data. Surv Geophys 23:207-249. https://doi.org/10.102 3/A:1015012821040

Egbert GD, Booker JR (1986) Robust estimation of geomagnetic transfer functions. Geophys J Int 87:173-194. https://doi.org/10.1111/j.1365246X.1986.tb04552.x

Egbert GD, Booker JR (1989) Multivariate analysis of geomagnetic array data: 1. The response space. J Geophys Res 94(B10):14227-14247. https://doi. org/10.1029/JB094iB10p14227

Egbert GD, Eisel M, Boyd OS, Morrison HF (2000) DC trains and Pc3s: source effects in mid-latitude geomagnetic transfer functions. Geophys Res Lett 27(1):25-28. https://doi.org/10.1029/1999GL008369

Hughes JW (1994) Magnetospheric ULF waves: a tutorial with a historical perspective. In: Engebretson MJ, Takahashi K, Scholer M (eds) Solar wind sources of magnetospheric ultra-low-frequency waves. American Geophysical Union, Washington, pp 1-18. https://doi.org/10.1029/ GM081p0001

Hughes WJ, Southwood DJ (1976) The screening of micropulsation signals by the atmosphere and ionosphere. J Geophys Res 81(19):3234-3240. https://doi.org/10.1029/JA081i019p03234

Jones AG, Spratt J (2002) A simple method for deriving the uniform field MT responses in auroral zones. Earth Planets Space 54:443-450. https://doi. org/10.1186/BF03353035

Kawano H, Yumoto K, Pilipenko VA, Tanaka Y-M, Takasaki S, lizima M, Seto M (2002) Using two ground stations to identify magnetospheric field line eigenfrequency as a continuous function of ground latitude. J Geophys Res. https://doi.org/10.1029/2001JA000274

Kelbert A, Egbert GD, Schultz A (2011) IRIS DMC data services products: EMTF magnetotelluric. Trans Func. https://doi.org/10.17611/DP/EMTF

Larsen JC, Mackie RL, Manzella A, Fiordelisi A, Rieven S (1996) Robust smooth magnetotelluric transfer functions. Geophys J Int 124:801-819. https:// doi.org/10.1111/j.1365-246X.1996.tb05639.x

McPherron RL (2005) Magnetic pulsations: their sources and relation to solar wind and geomagnetic activity. Surv Geophys 26:545-592. https://doi. org/10.1007/s10712-005-1758-7

Menk FW (2011) Magnetospheric ULF waves: a review. In: Liu W, Fujimoto M (eds) The dynamic magnetosphere. Springer, Berlin, pp 223-256. https:// doi.org/10.1007/978-94-007-0501-2_13

Menk FW, Mann IR, Smith AJ, Waters CL, Clilverd MA, Milling DK (2004) Monitoring the plasmapause using geomagnetic field line resonances. J Geophys Res 109:A04216. https://doi.org/10.1029/2003JA010097

Meqbel NM, Egbert GD, Wannamaker PE, Kelbert A, Schultz A (2014) Deep electrical resistivity structure of the northwestern U.S. derived from 3-D inversion of USArray magnetotelluric data. Earth Planet Sci Lett 402:290-304. https://doi.org/10.1016/j.epsl.2013.12.026

Murphy BS, Egbert GD (2017) Electrical conductivity structure of southeastern North America: implications for lithospheric architecture and Appalachian topographic rejuvenation. Earth Planet Sci Lett 462:66-75. https:// doi.org/10.1016/j.epsl.2017.01.009

Pilipenko VA, Federov EN (1993) Magnetotelluric sounding of the crust and hydromagnetic monitoring of the magnetosphere with the use of ULF waves. Ann Geofis 36(5-6):19-32. https://doi.org/10.4401/ag-4243

Pilipenko VA, Federov EN (1994) Magnetotelluric sounding of the crust and hydromagnetic monitoring of the magnetosphere with the use of ULF waves. In: Engebretson MJ, Takahashi K, Scholer M (eds) Solar wind sources of magnetospheric ultra-low-frequency waves. American Geophysical Union, Washington, pp 283-292. https://doi.org/10.1029/ GM081p0283 
Poulter EM, Allan W, Bailey GJ (1988) ULF pulsation eigenperiods within the plasmasphere. Planet Space Sci 36(2):185-196. https://doi. org/10.1016/0032-0633(88)90054-2

Smirnov MYu, Egbert GD (2012) Robust principal component analysis of electromagnetic arrays with missing data. Geophys J Int 190:1423-1438. https://doi.org/10.1111/j.1365-246X.2012.05569.x

Viljanen A (2012) Description of the magnetospheric/ionospheric sources. In: Chave AD, Jones AG (eds) The magnetotelluric method: theory and practice. Cambridge University Press, Cambridge, pp 96-121. https://doi. org/10.1017/CBO9781139020138.005

Vozoff K (1986) Magnetotelluric methods. Society of Exploration Geophysicists, Tulsa, p 763

Wait JR (1954) On the relation between telluric currents and the Earth's magnetic field. Geophysics 19(2):281-289. https://doi.org/10.1190/1.1437994 Wait JR (1982) Geo-electromagnetism. Academic Press, Cambridge, p 268 Waters CL, Menk FW, Fraser BJ (1991) The resonance structure of low latitude Pc3 geomagnetic pulsations. Geophys Res Lett 18(12):2293-2296. https:// doi.org/10.1029/91GL02550
Waters CL, Menk FW, Thomsen MF, Foster C, Fenrich FR (2006) Remote sensing the magnetosphere using ground-based observations of ULF waves. In: Takahashi K, Chi PJ, Denton RE, Lysak RL (eds) Magnetospheric ULF waves: synthesis and new directions. American Geophysical Union, Washington, pp 319-340. https://doi.org/10.1029/169GM21

Weidelt $P$ (1972) The inverse problem of geomagnetic induction. Zeitschrift für Geophysik 38:257-289

Weidelt P, Chave AD (2012) The magnetotelluric response function. In: Chave $A D$, Jones AG (eds) The magnetotelluric method: theory and practice. Cambridge University Press, Cambridge, pp 120-164. https://doi. org/10.1017/CBO9781139020138.006

Yang B, Egbert GD, Kelbert A, Meqbel NM (2015) Three-dimensional electrical resistivity of the north-central USA from EarthScope long period magnetotelluric data. Earth Planet Sci Lett 422:87-93. https://doi.org/10.1016/j. epsl.2015.04.006

\section{Submit your manuscript to a SpringerOpen ${ }^{\circ}$ journal and benefit from:}

- Convenient online submission

- Rigorous peer review

- Open access: articles freely available online

- High visibility within the field

- Retaining the copyright to your article

Submit your next manuscript at $\boldsymbol{\nabla}$ springeropen.com 